\title{
Determination of risk factors associated with childhood obesity and the correlation with adult obesity- A random cross sectional study from Nepal
}

\author{
Binay Kumar Raut ${ }^{1}$, Mukesh Kumar Jha ${ }^{2}$, Dijan Baidya ${ }^{3}$, Hari Sundar Shrestha ${ }^{3}$, \\ Subhash Sapkota ${ }^{3}$, Madhukar Aryal ${ }^{1}$, Prabodh Risal ${ }^{1}$, Shyam Sundar Malla ${ }^{1}$ \\ ${ }^{1}$ Department of Biochemistry, Kathmandu University School of Medical Sciences, Dhulikhel, Kavre, Nepal \\ ${ }^{2}$ Department of Physiology, Kathmandu University School of Medical Sciences, Dhulikhel, Kavre, Nepal \\ ${ }^{3}$ Faculty of Human Biology, Kathmandu University School of Medical Sciences, Dhulikhel, Kavre, Nepal
}

\section{Email address:}

binaymolbio@gmail.com (B. K. Raut),jhamukesh.jnp@gmail.com (M. K. Jha), dijanbaidya@gmail.com (D. Baidya), hari7sth@gmail.com (H. S. Shrestha), sapkota_suba@yahoo.com (S. Sapkota), madhukararyal@hotmail.com (M. Aryal), prabodh07@hotmail.com (P. Risal),shyam_malla@hotmail.com(S. S. Malla)

\section{To cite this article:}

Binay Kumar Raut, Mukesh Kumar Jha, Dijan Baidya, Hari Sundar Shrestha, Subhash Sapkota, Madhukar Aryal, Prabodh Risal, Shyam Sundar Malla. Determination of Risk Factors Associated with Childhood Obesity and the Correlation with Adult Obesity- A Random Cross Sectional Study from Nepal. American Journal of Health Research. Vol. 2, No. 4, 2014, pp. 134-139.

doi: 10.11648/j.ajhr.20140204.15

\begin{abstract}
Background: Obesity is a global problem that is rising at an astounding rate. The children and adolescent obesity are the burning issues. Body mass index (BMI) also called Quetelet Index (initially described by Quetelet in 1869), has become the measurement of choice to measure overweight and obesity in adults. To date there is no information on the extent of affliction due to overweight and obesity among children and their associated risk factors in Nepal. Objectives: The study was undertaken to find out if dietary, behavioral and physical factors contributed to risk of obesity in Nepalese children and adolescents around Kathmandu valley and to find out the association between childhood obesity with parental obesity. Methods: The study was conducted among subjects aged 5-19 years at four different locations; Lalitpur, Thimi, Kushadevi and Dhulikhel, Nepal. A total of 324 children and their 648 parents (324 father and mother each) participated in the study. Body Mass Index (BMI) was calculated according to the World Health Organization (WHO) criteria for all participants. Variables relation to socioeconomic status, dietary habits, physical factors and emotional well being were determined using a self-administered questionnaire. Results: As determined with the help of BMI, the factors like socioeconomic status and sedentary lifestyle were found to contribute to various conditions like obesity, underweight and overweight in children of various ages, although, prevalence of obesity was low compared to the other conditions. Also BMI of children was found to be positively and significantly correlated with father's and mother's BMI indicating its importance as a marker in progression of such health conditions in children. Conclusions: BMI proved to be a reliable indicator of adverse health conditions like obesity in Nepalese children and could contribute to understanding the role of the various risk factors of dietary, social and physical nature in the development of these conditions.
\end{abstract}

Keywords: Obesity, BMI, Underweight, Overweight

\section{Introduction}

Overweight and obesity are attributed to an enlargement or increased number of fat cells or a combination of both, which occurs when energy intake exceeds energy expenditure [1]. The classification of overweight and obesity is often interpreted according to the Body Mass
Index (BMI). The index provides a reliable indicator of body fatness for most people and is used to screen for weight categories that may lead to health problems.

Increase in overweight and obesity have become an important public health problem globally because of its adverse health consequences and prevalence rates are escalating at astounding rate worldwide. Even though the health consequences of obesity are most commonly seen 
during adulthood, the underlying factors of these diseases typically originate during childhood.

Childhood obesity is global health concern affecting all socio-economic groups, irrespective of age, sex or ethnicity. The rising prevalence of obesity cannot be addressed by a single etiology as multiple etiologies are responsible for this imbalance. Genetic, neuroendocrine, metabolic, psychological, environmental and socio-cultural factors play major role in the rising prevalence of childhood obesity worldwide. Regional urbanization and economic growth have been associated with a more sedentary lifestyle and increased consumption of high fat- and sugarladen diets both considered as risk factors for promoting childhood obesity. Studies have shown strong correlation between family history, sedentary lifestyle, socio-economic status, television watching, internet browsing, computer games, eating behavior, sleeping patterns and an increased prevalence of childhood obesity.

Recent data indicate a rise in obesity, both in children and adolescents in developing countries that are undergoing rapid nutrition and lifestyle transition and it often coexists with under nutrition due to wide socioeconomic disparities. Lowincome countries like Nepal experiences burden of infectious diseases as well as rising incidence of non-communicable diseases frequently associated with obesity [2].

Hence this study was undertaken to evaluate a number of risk factors commonly associated with childhood obesity as well as to determine the association of childhood obesity with parental obesity using BMI as an indicator.

\section{Methods}

\subsection{Study Design}

A cross sectional study design was adopted in this study. This study included children and adolescents aged 5 to 19 years and their parents from four different locations; Lalitpur, Thimi, Kushadevi and Dhulikhel, Nepal. Height and weight were measured and the Body Mass Index (BMI) was calculated.

\section{Anthropometric Variables}

\subsection{Height}

Height was measured with a non stretchable measuring tape by marking the scale on the house wall.

\subsection{Weight}

Weight was measured with a weighing scale with the participant standing with shoes removed and lightly clothed.

\subsection{Body Mass Index (BMI)}

The BMI for adults was calculated according to the WHO criteria by dividing the subject's mass in kilogram by the square of his or her height, typically expressed in metric [1].

$$
\text { Metric: } \mathrm{BMI}=\text { kilograms } / \text { meters }^{2}
$$

Data collection was performed by door to door visit at the morning and evening when the participants were met at home. Following informed consent, information relating to monthly income, dietary habits, physical and sedentary activities, emotional well being, smoking and alcohol consumption were collected using a self-administered questionnaire. Data was stratified by race and gender.

A child's weight status is determined using an age- and sex-specific percentile for BMI rather than the BMI categories used for adults because children's body composition varies as they age and varies between boys and girls. The Centre for Disease Control and Prevention (CDC) Growth Charts were used to determine the corresponding BMI-for-age and sex percentile. For children and adolescents (aged 2-19 years):

- Overweight is defined as a BMI at or above the 85 th percentile and lower than the 95 th percentile for children of the same age and sex.

- Obesity is defined as a BMI at or above the 95th percentile for children of the same age and sex.

\section{Data Processing and Analysis}

Data gathered were checked for completeness and accuracy. Necessary coding was used to simplify the collected data which were then further processed.

The data analysis was carried out using SPSS (version 11.5 software (SPSS Inc., 233 South Wacker Drive, 11th Floor, Chicago, IL 60606-6307). Pearson's correlation coefficients were used for continuous variables to find the association of childhood obesity with parental obesity. The level of significance of all tests was taken at $P<0.05$.

\section{Results}

A total of 324 children participated in the study, out of which, $172(53.1 \%)$ were male and $152(46.9 \%)$ were female.

Of the 324 respondent children, 10 (3.1\%) were overweight and $2(0.6 \%)$ were obese, $210(64.8 \%)$ were underweight and $102(31.5 \%)$ were of a normal BMI (Fig $1)$.

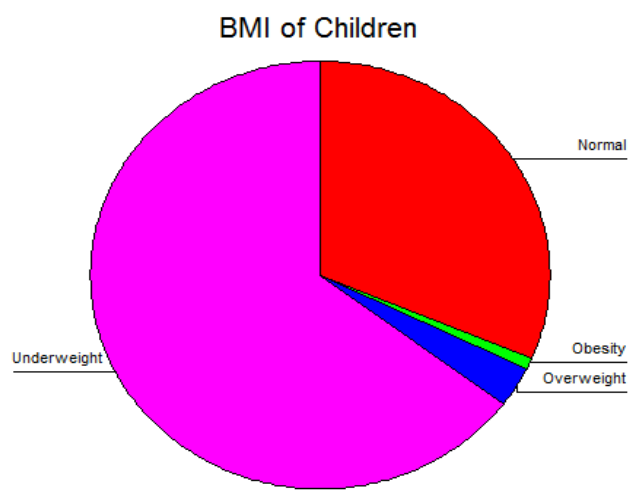

Fig 1. BMI of Children 
Among the total population of fathers, $137(42.3 \%)$ were overweight, $14(4.3 \%)$ were obese, $152(46.9 \%)$ were of a normal BMI and 21 (6.5\%) were underweight (Fig 2).

BMI of Father

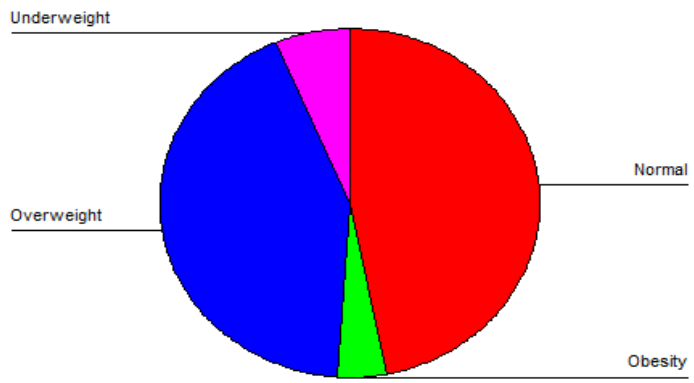

Fig 2. BMI of Father

Among the total population of mothers, $158(48.8 \%)$ were overweight and $36(11.1 \%)$ were obese, $116(35.8 \%)$ were of a normal BMI and $14(4.3 \%)$ were underweight (Fig 3).

\section{BMI of Mother}

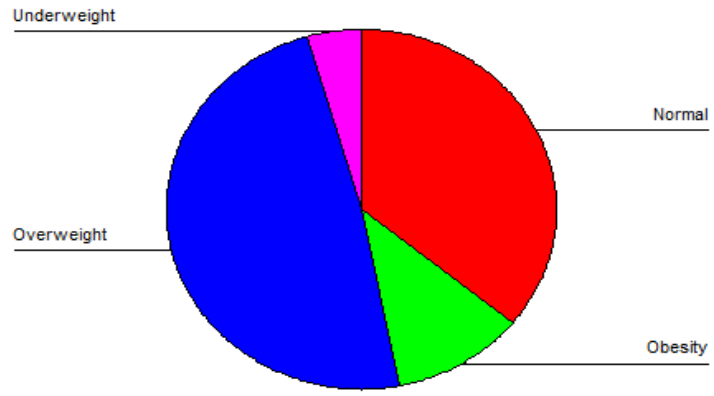

Fig 3. BMI of Mother

For determination by age, the criteria defined by CDC BMI-for-Age Growth Charts was used and accordingly out of 324 subjects aged between 5-19 years only 3 children aged 14,15 and 16 were found to be obese.

Table 1. No. of children with their BMI group based on Age

\begin{tabular}{llllll}
\hline Age & Underweight & Normal & Overweight & Obesity & Total \\
\hline 5 & 7 & 22 & - & - & 29 \\
6 & 5 & 12 & - & - & 17 \\
7 & 5 & 9 & - & - & 14 \\
8 & 4 & 13 & 1 & - & 18 \\
9 & 6 & 14 & - & - & 20 \\
10 & 3 & 16 & 1 & - & 20 \\
11 & 4 & 15 & 2 & - & 21 \\
12 & 4 & 15 & - & - & 19 \\
13 & 2 & 17 & 4 & - & 23 \\
14 & 4 & 21 & 4 & 1 & 30 \\
15 & - & 16 & 2 & 1 & 19 \\
16 & 3 & 22 & - & 1 & 26 \\
17 & 4 & 22 & - & - & 26 \\
18 & 3 & 16 & - & - & 19 \\
19 & 2 & 21 & - & - & 23 \\
Total & 56 & 251 & 14 & 3 & \\
\hline
\end{tabular}

The distribution of the children according to the age and BMI is shown in the Table 1 and Figure 4.

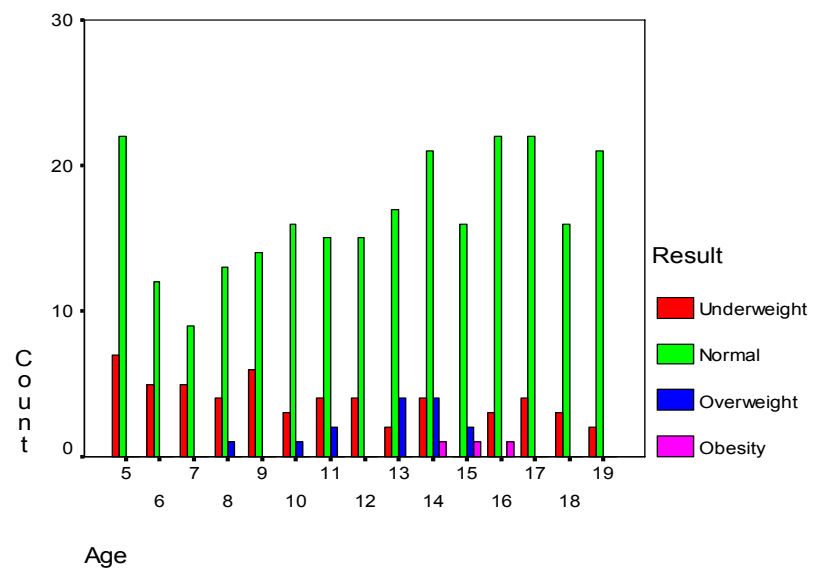

Fig 4. BMI group of Children based on Age

Out of 172 males in children; $6(3.5 \%)$ males were overweight and $2(1.2 \%)$ males were obese but most of the males, $121(70.3 \%)$ were found out to be underweight and the rest 43 (25\%) were of normal BMI. Similarly out of 152 females in children, only $4(2.6 \%)$ females were overweight and no female was obese but most of the females 89 (58.6\%), were underweight and $59(38.8 \%)$, were found out to be of a normal BMI.

The categorization of the total population according to gender and BMI is shown in the given Figure 5.

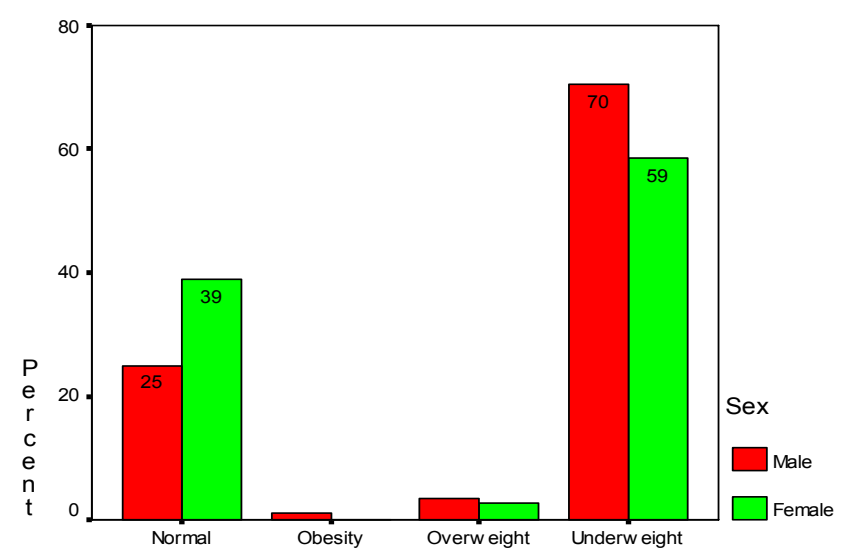

BMI of Children

Fig 5. BMI of Children based on sex

Based upon socio-economic status, most of the children were found to be underweight and normal. Maximum number of children was underweight i.e. $69 \%, 65 \%$ and $52 \%$ with family monthly income less than Nepalese rupee (NPR) 10000, between NPR 10000-20000 and more than NPR 20000 respectively. Only $1.7 \%$ of the children were found to be obese as seen in the family with monthly income ranging from NPR 10000-20000. 


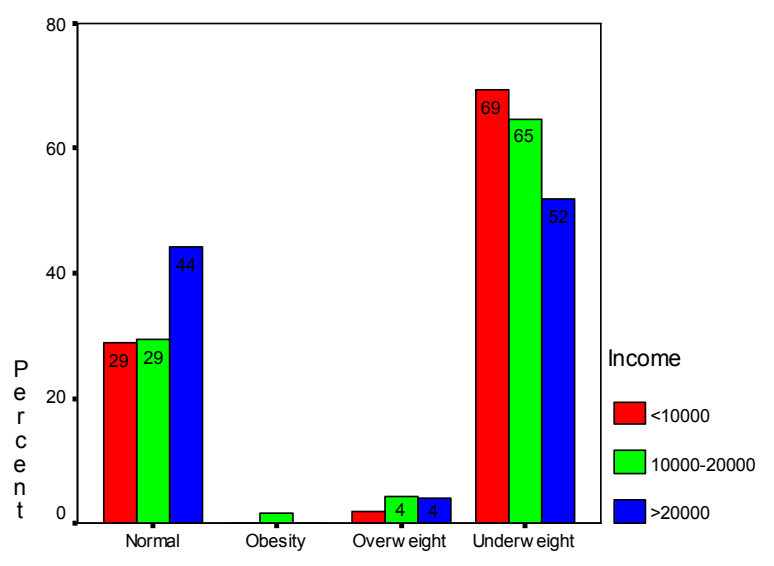

BMl of Children

Fig 6. BMI of Children based on socio-economic status

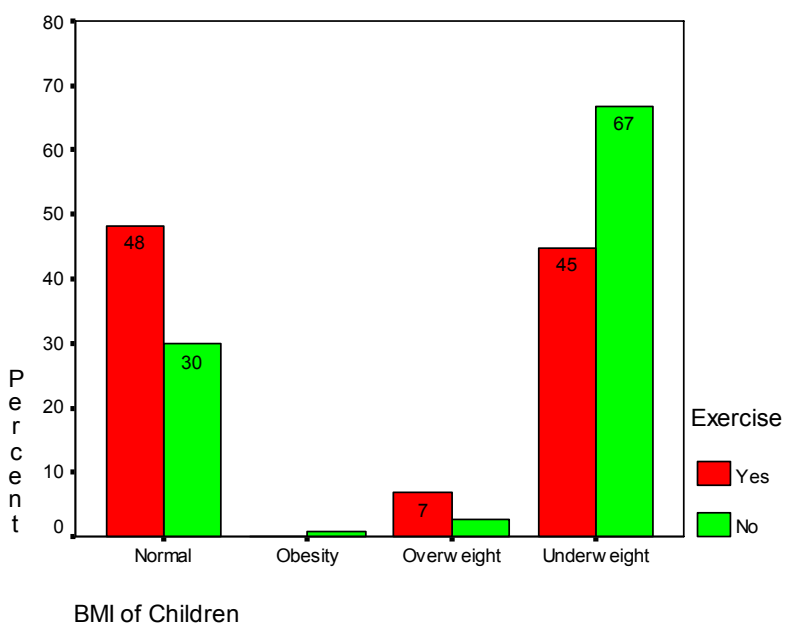

Fig 7. BMI of Children based on exercise

Of the total population, only $0.7 \%$ of the children were found to be obese who were not involved in physical exercise. While $48 \%$ of the children involved in physical exercise were found to be normal. Prevalence of underweight children were more with those not involved in physical exercise than with those involved in physical exercise.

In the bivariate analysis (Pearson correlation test) of sample population the child's BMI was found to be positively and significantly correlated with father's BMI which is depicted in the given Figure 8.

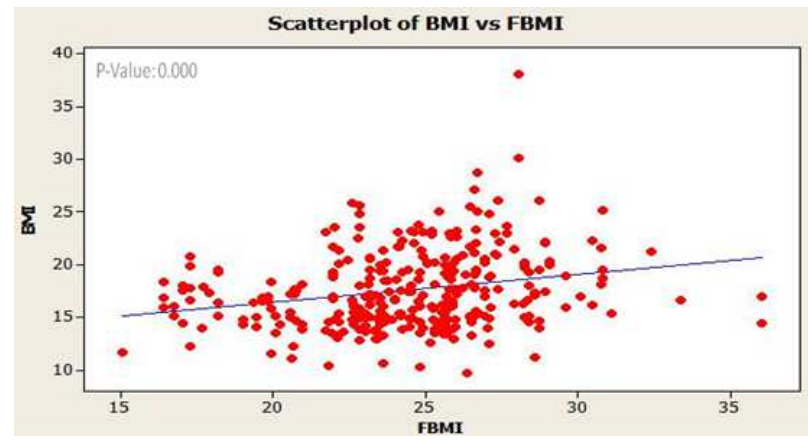

Figure 8. Correlation of Child's BMI with Father's BMI
Figure 8 shows mild positive correlation between Child's BMI \& Father's BMI. The children's BMI was found to be fairly correlated with father's BMI in the total population (irrespective of gender). But the correlation coefficient was lower $(0.238 * *)$.

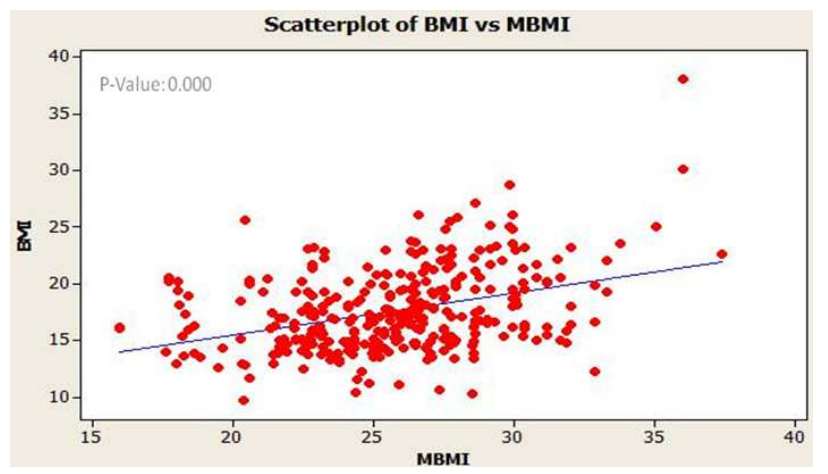

Figure 9. Correlation of Child's BMI with Mother's BMI

Figure 9 shows mild positive correlation between Child's BMI \& Mother's BMI. In the bivariate analysis (Pearson correlation test) of sample population children's BMI was found to be positively and significantly correlated with Mother's BMI which is depicted in the given Figure 9.

The children's BMI was found to be fairly correlated with mother's BMI in the total population (irrespective of gender). The correlation coefficient was lower $\left(0.373^{* *}\right)$.

\section{Discussion}

Despite rapidly increasing urbanization (4.9\% per year), about $90 \%$ of Nepal's inhabitants live in rural areas [4]. Two of every five Nepalese live below the absolute poverty line, and half of all people in rural Nepal are poor [4]. Similar to many other low- and middle-income countries, Nepal is currently experiencing significant lifestyle changes that spring from various social and demographic changesan "epidemiological transition" that includes urbanization and migration. Insurgency and political instability drive migration. Moreover, high unemployment and underemployment (17.4\% and 32.3\%, respectively) compel people to choose between remaining in a vicious circle of poverty and migrating to seek better livelihood opportunities both within and outside the country [4].

Socioeconomic status affect overweight and obesity prevalence among adults and children, and these influences may vary according to the economic context. Due to sluggish economic growth of Nepal, most of the children are more likely to be at risk of undernourishment. However, middle income people are at risk of overweight and obesity.

There is increasing evidence that underweight and overweight may exist among family members within the same household. We found that children from families that eat together regularly are less likely to be overweight or obese. One reason for this is that these children generally eat a healthier diet [4-6]. A second reason is that family meals prevent children from eating in front of the television, which 
may lead to "mindless eating" and higher energy intake [7-9].

Genetic factors can have a great effect on individual predisposition. Genetic influence has a limited effect on the timing of childhood obesity. The older the child gets affects the severity of obesity, especially during adolescence. It is suggested that the genes influencing adiposity have differential effects at distinct childhood ages and may not be exerted equally throughout the life cycle $[10,11]$. It is not clear in our study whether the relationship between parental BMI and severity of obesity in their children is due to genetic or environmental factors.

It has been hypothesized that a steady decline in physical activity among all age groups has heavily contributed to rising rates of obesity all around the world. Numerous studies have shown that sedentary behaviors like watching television and playing computer games are associated with increased prevalence of obesity $[12,13]$. Furthermore, parents report that they prefer having their children watch television at home rather than play outside unattended because parents are then able to complete their chores while keeping an eye on their children [14].

Since both parental and children's choices fashion these behaviors, it is not surprising that overweight children tend to have overweight parents and are themselves more likely to grow into overweight adults than normal weight children [15]. In response to the significant impact that the cultural environment of a child has on his/her daily choices, promoting a more active lifestyle has wide ranging health benefits and minimal risk, making it a promising public health recommendation. In our study, as in other studies of the effect of risk factors related to children's lifestyle, normal-weight children were more physically active and engaged less in sedentary activities.

\section{Conclusion}

From the findings of the present study it could be concluded that BMI serves as a simple and efficient indicator of different categories associated with body fat like underweight, overweight and obesity in children. It can also serve as a predictor for the role of various risk factors in development of obesity namely socioeconomic status and lifestyle.

Also a positive correlation between children's BMI and parents' BMI indicated its significance as a marker in progression of such health conditions prospectively in children.

\section{References}

[1] K. Park's Textbook of Preventive and Social Medicine. $17^{\text {th }}$ edition. India: M/s Banarsidas Bhanot Publishers; 2002. Obesity; p.298.

[2] Abhinav Vaidya, Suraj Shakya and Alexandra Krettek. Obesity Prevalence in Nepal: Public Health Challenges in a Low-Income Nation during an Alarming Worldwide Trend. Int J Environ Res Public Health. 2010 June; 7(6): 27262744.
[3] Institute of Medicine, National Academy of Sciences. Nutrition During Pregnancy. Washington, DC: National Academy Press; 1990.

[4] Curhan GC, Willett WC, Spiegelman D, Colditz GA, et al. Birth weight and adult hypertension and obesity in women. Circulation. 1996; 94:1310-5.

[5] Champe Pamela C, Harvey Richard A. Lippincott's Illustrated Reviews. Biochemistry. $4^{\text {th }}$ edition. New Delhi: Wolters Kluwer (India) Pvt. Ltd; 2008. Obesity; p.349.

[6] World Health Organization. Obesity: Preventing and Managing the Global Epidemic. World Health Organization Technical Support Series No. 894. Geneva, Switzerland: World Health Organization; 2000.

[7] Dietz WH, Gortmaker SL. Preventing obesity in children and adolescents. Annu Rev Public Health. 2001; 22:337 53.

[8] Ghaffar A, Reddy KS, Singhi M. Burden of noncommunicable diseases in South Asia. Br. Med. J. 2004; 328:807-810. [PMC free article] [Pub Med]

[9] De Onis M, Blossner M. Prevalence and trends of overweight among pre-schoolchildren in developing countries. Am J Clin Nutr. 2000; 72:1032-9.

[10] World Health Organization [http://www.who.int/en/]

[11] de Onis M, Blossner M, Borghi E.Global prevalence and trends of overweight and obesity among preschool children. Am J Clin Nutr 2010; 92:1257-64

[12] Nepal Demographic and Health Survey 2006. Ministry of Health and Population, New ERA, and Macro International Inc; Kathmandu, Nepal: 2007.

[13] Cui Z, Huxley R, Wu Y, Dibley MJ. Temporal trends in overweight and obesity of children and adolescents from nine Provinces in China from 1991-2006. Int J Pediatr Obes 2010; 5:365-74.

[14] Raj M, Sundaram KR, Paul M, Deepa AS, Kumar RK. Obesity in Indian children: time trends and relationship with hypertention. Natl Med J India 2007: 20: 288-93.

[15] Gelal B, Aryal M, Das BKL, Bhatta, Lamsal M and Baral N. Assessment of iodine nutrition status among school children of Nepal by urinary assay. Soutneast Asian J Trop Med Public Health 2009; 40: 538-43.

[16] Jacobson P, Torgerson JS, Sjo“stro“m L, Bouchard C. Spouse resemblance in body mass index: effects on adult obesity prevalence in the offspring generation. Am J Epidemiol 2007; 165:101-8.

[17] Vasudevan D M, Sreekumari S. Text book of Biochemistry. $4^{\text {th }}$ edition. New Delhi: Jaypee Brothers Medical Publishers (India) Pvt. Ltd; 2005. Obesity; p.324.

[18] Sundblom E, Petzold M, Rasmussen F, Callmer E, Lissner L. Childhood overweight and obesity prevalences levelling off in Stockholm but socioeconomic differences persist. Int $J$ Obes (Lond) 2008; 32: 1525-30.

[19] Goran MI. Metabolic precursors and effects of obesity in children: a decade of progress, 1990-1999. Am J Clin Nutr.2001; 73:158-71.

[20] Whitaker RC, Wright JA, Pepe MS, Seidel KD, Dietz WH. Predicting obesity in young adulthood from childhood and parental obesity. N Engl J Med. 1997; 337:869 -73. 
[21] Cara B Ebbeling, Dorota B Pawlak, David S Ludwig. Childhood obesity: public-health crisis, common sense cure. Lancet 2002, 360: 473-82.

[22] Lazarus R, Baur L, Webb K, Blyth F: Body mass index in screening for adiposity in children and adolescents: systematic evaluation using receiver operating characteristic curves. Am J Clin Nutr 1996, 63:500-506.

[23] Stevens J: Obesity, fat patterning and cardiovascular risk. Adv Exp Med Biol 1995, 369:21-27.

[24] Shamail Zafar, Israr ul Haque, Anjum Rasheed Butt, Huda G Mirza, Fuad Shafiq, Ameed ur Rehman, Nusrat Ullah Ch, Relationship of body mass index and waist to hip ratio measurement with hypertension in young adult medical students, Pak J Med Sci July - September 2007 Vol. 23 No. 4 574-579

[25] Awasthi Janak Raj, Uprety Bipashwi Nath. Correlation of Anthropometric Index with Blood Pressure. Kathmandu University School of Medical Sciences (Nepal); 2010 July. p. $15-16$.

[26] Nepal Demographics Profile 2009 Available online: http://www.indexmundi.com/nepal/demographics_profile.ht $\mathrm{ml}$ (accessed 15 January 2010).

[27] Veugelers PJ, Fitzgerald AL, Johnston E. Dietary intake and risk factors for poor diet quality among children in Nova Scotia. Can J Public Health 2005; 96:212-6.

[28] Gillman MW, Rifas-Shiman SL, Frazier L, Rockett HRH, Camargo CA, Field AE. Family dinner and diet quality among older children and adolescents. Arch Fam Med 2000; 9:235-40.

[29] Neumark-Sztainer D, Hannan PJ, Story M, Croll J, Perry C. Family meal patterns: Associations with sociodemographic characteristics and improved dietary intake among adolescents. J Am Diet Assoc 2003; 103:317-22.

[30] Robinson TN. Television viewing and childhood obesity. Pediatr Clin North Am 2001; 48:1017-25.
[31] Caroli M, Argentieri L, Cardone M, Masi A. Role of television in childhood obesity prevention. Int $J$ Obes Relat Metab Disord 2004;28(Suppl 3):S104-8.

[32] National Center for Addiction and Substance Abuse at Columbia University. The importance of family dinners. New York: The Center; 2003. Available: www.casacolumbia.org/Absolutenm/articlefiles/Family_Din ners_9_03_03.pdf (accessed 2005 Mar 21).

[33] Safer DL, Agras WS, Bryson S, Hammer LD. Early body mass index and other anthropometric relationships between parents and children. Int J Obes Relat Metab Disord 2001; 25: $1532-1536$

[34] Stunkard AJ, Berkowitz RI, Stallings VA, Cater JR. Weights of parents and infants: is there a relationship? Int J Obes Relat Metab Disord 1999; 23: 159-162.

[35] Kral JG, Biron S, Simard S, Hould FS, Lebel S, Marceau S et al. Large maternal weight loss from obesity surgery prevents transmission of obesity to children who were followed for 2 to 18 years. Pediatrics 2006; 118: 1644-1649.

[36] Swinburn B, Egger G: Preventive strategies against weight gain and obesity. Obes Rev 2002, 3:289-301.

[37] Tremblay MS, Willms JD: Is the Canadian childhood obesity epidemic related to physical inactivity? Int $J$ Obes Relat Metab Disord 2003, 27:1100-1105.

[38] Gordon-Larsen P, Griffiths P, Bentley ME, Ward DS, Kelsey K, Shields K, Ammerman A: Barriers to physical activity: qualitative data on caregiver-daughter perceptions and practices. Am J Prev Med 2004, 27:218-223.

[39] Carriere G: Parent and child factors associated with youth obesity. Statistics Canada; 2003.

[40] Barlow SE and the Expert Committee. Expert committee recommendations regarding the prevention, assessment, and treatment of child and adolescent overweight and obesity: summary report. Pediatrics 2007;120 Supplement December 2007:S164-S192. 